\title{
ESTRANGEIRAS, PRISÕES E IDENTIDADE(S): UMA REFLEXÃO A PARTIR DA LEI N 13.445, DE 24 DE MAIO DE 2017
}

Geraldo Ribeiro de Sá ${ }^{1}$

Resumo: Dialoga-se com presidiárias estrangeiras mediadas por pesquisadoras(es), que lhes dão voz e outros estudiosos da população prisional. Debate-se com a Lei de Migração, Execução Penal e a Constituição Federal. Expõe-se inovação em conteúdo dos conceitos de não nacional e de estrangeira, em itálico. Observa-se predominância do tráfico de drogas, com destaque da cocaína; prevalência de jovens, mães, primárias, com emprego declarado, escolaridade e status superior à média das brasileiras presas; questões relacionadas às motivações para o crime, ao gênero, à etnia e à cor da pele.

Palavras-chave: Prisão. Gênero. Estrangeiras. Diversidade. Tráfico de drogas.

Foreign women, prisons, and identity (ies): a reflection based on Act No. 13.445, of May 24, 2017

\begin{abstract}
This paper listens to foreign imprisoned women having researchers as facilitators, who give them voice, and other scholars of the prison population. The Migration Law, Criminal Execution and the Federal Constitution are debated. Content innovation for the concepts of non-national and foreign women is exposed in italics. Note: A predominance of drug trafficking, especially cocaine; a prevalence of young people, mothers, first offenders, with declared employment, education, and a higher status than the average of Brazilian prisoners; issues related to crime motivations, gender, ethnicity, and skin color.
\end{abstract}

Keywords: Prison. Gender. Foreign women. Diversity. Drug trafficking.

\section{Introdução}

Estrangeiras, no plural e em itálico, justifica-se pela ausência dessa palavra na LDM (Lei de Migração), vigente a partir de 2017, que a substituiu por migrante, legitima-se também pela diversidade das migrantes em razão da procedência, cor da pele, etnia, idade, profissão, língua, estado civil, costumes, religião e outras e pelo detalhe da distinção entre não nacional, expressão ampla, e estrangeira, conceito usado por Bumachar (2016). A especificidade desse conceito dar-se-á por seu dinamismo que se manifesta pelo longo e contraditório processo de conversão das prisioneiras ao modo de vida entre muros ou fronteiras locais, nacionais e transnacionais. Apesar da condição de migrantes e suas particularidades, as estrangeiras estão próximas das brasileiras em razão da CF (Constituição

\footnotetext{
${ }^{1}$ Doutor em Ciências Sociais pela PUC/SP, aposentado da UFJF, filiado ao CONPEDI e ao CERU/USP. Este artigo é uma produção do autor enquanto membro do Grupo de Estudos "Migrações e Identidade", organizado pelo CERU/USP. Pesquisador do Grupo "Fluxos migratórios contemporâneos para o Brasil" - CNPq/18/11/18 Líder: Mário Antônio Eufrásio. geralr@terra.com.br
} 
Federal) prescrever que "Todos são iguais perante a lei, sem a distinção de qualquer natureza, garantindo-se aos brasileiros e aos estrangeiros o direito à vida, à liberdade, à igualdade, à segurança e à propriedade" [...] (BRASIL, 1988, art.5 caput.). Além da CF, a LEP (Lei de Execução Penal), que rege as instituições destinadas "ao condenado, ao submetido à medida de segurança, ao preso provisório e ao egresso", (art. 82), seja homem ou mulher, nacional ou estrangeira, afirma que "não haverá qualquer distinção de natureza racial, social, religiosa ou política", art. $3^{\circ}$, parágrafo único (BRASIL, 1988).

A LEP diz que "A mulher será recolhida a estabelecimento próprio e adequado a sua condição pessoal", acrescentando, de imediato, que "O mesmo conjunto arquitetônico poderá abrigar estabelecimentos de destinação diversa desde que devidamente isolados" (art. 82, $\S 1^{\circ}$ e $2^{\circ}$ ). Por outro lado, nenhuma das três leis citadas menciona a obrigatoriedade de prisões exclusivas para não nacionais. Como se verá, no desenvolvimento destas reflexões, presas estrangeiras e presas brasileiras convivem no mesmo estabelecimento na PFC (Penitenciária Feminina da Capital), em São Paulo, e na PFDF (Penitenciária Feminina do Distrito Federal), em Brasília e noutras.

Antes e durante a elaboração destas reflexões, seu autor foi motivado e alimentado, fundamentalmente, pela leitura de Diniz (2015) e Bumachar (2016), cujos livros se tornaram fontes primárias. Outros (as) autores (as) foram lidos, na condição de fontes secundárias.

Conforme se tem procedido em outros trabalhos, o que se coletou das fontes foi tratado à luz das orientações da técnica de "análise de conteúdo"2. Optou-se por apresentar este texto percorrendo os tópicos seguintes: a) vozes estrangeiras; b) tradução de não nacionais para estrangeiras.

\section{Desenvolvimento}

\section{Vozes estrangeiras}

A presença de "estrangeiras", nas prisões brasileiras, tem um longo processo de registro e identificação, marcados por detalhes e características que vão dos mais simples aos mais complexos, acompanhando o movimento das políticas públicas, orientadas para a construção de prisões, alas ou de apenas celas exclusivas para mulheres. Um dos primeiros registros foi feito entre 1976 e 1978, por Lemgruber (1983, p. 52), ao distribuir as internas da Penitenciária Talavera Bruce, na cidade do Rio de Janeiro, segundo a "Naturalidade e/ou

\footnotetext{
${ }^{2}$ A "análise de conteúdo" é "um método de pesquisa usado para analisar a vida social mediante interpretação de palavras e imagens contidas em documentos, filmes, obras de arte, música e outros produtos culturais e da mídia" (JOHNSON, 1997, p. 12).
} 
Nacionalidade". Entre as 172 internas, à época, foi constatada a presença de duas "estrangeiras" procedentes dos Estados Unidos da América, porém sem quaisquer outros detalhes apresentados pela socióloga a respeito das norte-americanas. Mais tarde, Soares e Ilgenfritz (2002, p 36-37) assinalaram que em todos os presídios do Estado do Rio de Janeiro, há separações: "mais velhas de mais novas; estrangeiras de brasileiras; crentes das demais". Destacaram a "estrangeira" "Z", 44 anos, que tem pós-graduação e gostaria de trabalhar na enfermaria. As duas pesquisadoras não mencionaram outros detalhes sobre "Z", nem mesmo a respeito da instituição prisional a qual pertencia. Entretanto, ao investigar a Talavera Bruce, elas encontraram uma realidade já muito diferente daquela descrita por Lemgruber entre 1976 e 1978, no que se refere às presas não nacionais. Há um pavilhão especial para as "estrangeiras", portanto já não são apenas duas norte-americanas, pelo contrário, são muitas. "O pavilhão das estrangeiras parece uma torre de Babel, pela diversidade de línguas faladas, mas foi sentida uma enorme solidariedade entre as presas" (SOARES, ILGENFRITZ, 2002, p. 37 e 96). A quantidade é expressiva. São 23 não nacionais de diferentes países como África do Sul, Angola, Chile, Colômbia, Espanha, Estados Unidos, Holanda, Portugal, República da Guiné e Rússia. Fala-se em Torre de Babel. Diversidade de línguas e de nacionalidades, porém há igualdade entre si marcada pela enorme solidariedade. Outro ponto distinto observado entre as não nacionais e, o que as difere das brasileiras, refere-se ao abandono e certas discriminações: "Muitas se sentem completamente abandonadas pela distância de seus familiares, pois sequer recebem correspondência. Todas reclamam de serem discriminadas quanto ao trabalho, onde há preferência por brasileiras". Acrescentaram ainda as duas autoras, na mesma página: "Nenhuma recebe visita, e várias denunciaram a falta de apoio das embaixadas de seus países, para resolver questões pessoais e processuais".

$\mathrm{Na}$ medida em que as pesquisas sobre estabelecimentos penais femininos vão se tornando mais recentes, as informações a respeito de estrangeiras, em seu interior, crescem em números e em detalhes, inclusive, as relacionadas à arquitetura dos prédios, ao pessoal administrativo e equipamentos. Assim, Diniz (2015) detectou e descreveu a presença de "estrangeiras" em vários lugares de seu trabalho feito a respeito da PFDF, com os seguintes destaques.

\section{As russas}

"Elas chegam solitárias, todas por causa de droga nas cavidades naturais" (DINIZ, 2015, p. 19). Naturais porque oferecidas pelo corpo (anus, vagina, boca, estômago), "nas quais se escondem cápsulas" ou, também, nas cavidades construídas (fundo falso de mala ou 
bolsa, cintos grudados com o corpo, bainhas de vestuários, fundo de calçados), onde depositam papelotes e outras embalagens.

As cartas, embora raras e inesperadas, escritas em dialetos e não em russo, exigem muitas habilidades dos censores da cadeia para lê-las. São meios de comunicação já quase em desuso entre pessoas livres, porém adquirem significado muito especial e, sobretudo, simbólico, quando usadas como recurso à transposição de muros e grades prisionais e, com maior ênfase, quando se conectam encarceradas com seus países de origem.

Ao chegar, as cartas provocavam: "O burburinho de vez são as russas". "E não é russo mesmo, parece ser um dialeto esquisito". [...]. "O homem já tentou de tudo para decifrar garranchos cuja maior indiscrição é ornamentar álbuns de fotografia da neve" (DINIZ, 2015, p. 19). Os sinais gráficos estavam mais para rabiscos do que para letras. Além dos garranchos, as cartas eram ornamentadas de "fotografia da neve". Garranchos e motivos de burburinho para "O homem da inteligência" e demais funcionários, bem como para as prisioneiras presentes ao ato, mas não para as russas.

\section{Laila, a marroquina}

"A moça era de uma magrém desconhecida pelas bandas de cá, tinha porte de gente fina" (DINIZ, 2015, p. 9). Ao se destacar pela magreza, combinada com "porte de gente fina", Laila assemelhava mais à colombiana Juanita do que à maioria das quase setecentas mulheres presas na PFDF, uma totalidade formada por "presas provisórias, sentenciadas e em medida de segurança” (as loucas), de acordo com Diniz (2015, p. 112). Aliás, magreza somada ao "porte de gente fina" resulta em tipo esbelto, sinônimo de beleza e antônimo de feiura. O perfil de Laila pressupõe certa urbanidade, bom trato, alguma educação refinada, que geralmente não se aprende na rua. A via pública era o hábitat e a procedência de grande número das internas, o que está bem tipificado com o perfil de Dona Feia: "Corpo maltrapilho da rua ganhou novo couro; agora se banha, penteia cabelo e usa batom. A médica elogia o colorido". "[...] Dona feia não tem casa, só conheceu telhado no presídio; não tem registro, renasceu pelo crime" (DINIZ, 2015, p. 92). Tal perfil em nada se aplica ao retrato escrito de Laila.

Além do porte, a marroquina se destacava das demais também pela maternidade. É mãe do menino Samir. Tal condição dentro dos muros da cadeia sempre foi e continua sendo comovente, inclusive, na sensibilidade do legislador. Desta forma, a CF (Constituição Federal) é explícita: "às presidiárias serão asseguradas condições para que possam permanecer com seus filhos durante o período de amamentação" (art. $5^{\circ}$, L). Por sua vez, a 
LEP, alterada pela Lei n. 11. 942/2009, no art. 83, §2º́ é mais explícita e detalhista do que a Carta Magna: Outras exigências destinadas ao espaço prisional feminino, onde for que ele se encontre, foram incorporadas pela LEP. Esse mesmo dispositivo legal, conforme a emenda produzida pela Lei n. 11. 942/2009, art. 89, caput, é explícita e impositiva quanto ao direito da criança de permanecer amparada pela mãe presa, em creche: “a penitenciária de mulheres será dotada de seção para gestantes e parturientes e de creche para abrigar maiores de 6 (seis) meses e menores de 7 (sete) anos, com a finalidade de assistir a criança desamparada cuja responsável estiver presa”. Observa-se que a lei não faz qualquer distinção de nacionalidade, isto é, se estrangeira ou brasileira, como no presente caso.

A ausência de eficácia da lei propicia iniciativas ao livre arbítrio da administração prisional: "A lei diz que criança vive sete anos em presídio, desde que haja creche como território exclusivo. Mas a regra do presídio feminino da capital federal é breve, com seis meses criança deve conhecer mundo sem grade, fumaça e sirene”, conforme escreveu Diniz (2015, p. 109), a respeito do menino Samir.

\section{Rita Roberta, a fronteiriça}

O perfil de Rita Roberta assemelha-se à aparência de Laila e Juanita, além de ser "mulher forte determinada. De sangue migrante, estudou medicina na fronteira, mas se preparava para ser engenheira" (DINIZ, 2015, p. 129). O fato de ter estudado medicina indica alta escolaridade e expressiva dedicação aos estudos, visto que, pela regra geral, esse curso é de grande demanda. Não se informou, igualmente, se a migrante se graduou ou não em medicina. Rita Roberta preparava-se para ser engenheira, o que orienta ao leitor deduzir que frequentava um segundo curso superior. Ser portador de curso superior completo ou incompleto é uma raridade entre presos (as) comuns, sobretudo, no Brasil. Sua escolaridade, por si só, já confere à prisioneira destaque das pares.

Além de expressiva escolaridade, Rita Roberta tem força física e liderança, sabe o que quer e luta por isso. "Chegou com a altivez de quem não é gente da rua. A pele tem cor de lua fraca, os olhos parados e sem brilho anunciam elegância condenada a sumir em breve" (DINIZ, 2015, p. 130) [...]. Destoando de seu perfil estão “os olhos parados e sem brilho" que "anunciam elegância condenada a sumir em breve". O "sumir em breve" depende da decisão do júri, pois o que Rita Roberta mais fez durante o ano e meio de cadeia "foi esperar o dia em que o júri diria se é matadora cruel ou matadora no direito". Se "matadora no direito", isto é, em legítima defesa, por exemplo, e em sendo absolvida continuaria cuidando do menino Arthur e dos demais filhos, em liberdade. Mas, se condenada porque "matadora cruel", já teria 
confidenciado, em bilhete de próprio punho, a determinação de suicídio imediato, daí “os olhos parados e sem brilho" (DINIZ, 2015, p. 129-132).

A visibilidade da migrante presa salienta-se mais ainda pelo privilégio de ser "mãe do menino Arthur, o rei do presídio". Arthur é “o rei” por diversos motivos.

“O menino é sorridente". "Como todos os nascidos em presídio estranha homem e não se oferece a mulher de preto" (DINIZ, 2015, p. 129). Contudo, Arthur estranha homem porque, dentre outras razões, desde o nascimento vive cercado apenas de mulheres 24 horas por dia, da mesma forma que "não se oferece a mulher de preto, ou seja, às escoltas ou guardas".

"É o mais adulto dos bebês da Ala A, há onze meses tem uma banheira de plástico como berço". Arthur, filho de Rita Roberta, teve melhor sorte do que Samir, filho de Laila. Enquanto este cumpriu o costume criado pela administração, o que virou regra geral: "com seis meses criança deve conhecer mundo sem grade, fumaça e sirene”, aquele já se encontra "há onze meses" na Ala A da PFDF. A permanência de onze meses o transformou no "mais adulto dos bebês" de sua Ala. Não há relato justificando tal privilégio concedido ao "rei do presídio". A diferença de decisões da administração prisional envolvendo esses dois bebês, contrariando a legislação vigente, comprova mais uma vez o distanciamento entre fatos e normas no cotidiano de uma instituição prisional, bem como o poder discricionário do administrador.

O status de "rei" da penitenciária, além de destacar o prestígio do "menino Arthur" de seus pares e de toda a população prisional da PFDF, expressa inversão das normas costumeiras e da tradição. É trivial o prestígio do pai ou da mãe conferir posição social ao filho, mesmo na prisão. Para exemplificar, cita-se o caso de Edinho: "Um príncipe em Tremembé”: - “O Edinho chegou hoje! Exclamavam. - Cara, o filho do Pelé está aqui!” (FILLÓ, 2019, p. 71-76). Porque um príncipe? Sendo Pelé, um rei, Edinho, seu filho, por costume e tradição, é um príncipe. Arthur, pelo contrário, cria o insólito, derruba costumes e tradições. É ele quem confere e projeta a visibilidade de Rita Roberta, sua mãe. "Ninguém a desconhece, pois é mãe do menino Arthur, o rei do presídio”. Ora, mãe de rei é no mínimo princesa.

“A mãe é líder e cabrita de território" (DINIZ, 2015, p. 130), isto é, alcaguete ou delatora. A situação de "cabrita de território", de levar informações confidenciais de colegas à direção prisional é violação grave do "código" dos (as) ou presos (as) em qualquer tipo de estabelecimento penal. No entanto, Rita Roberta continua viva. Sua integridade física, pelo que se consta, ainda não sofreu ameaças. Há pelo menos duas hipóteses para justificar tal 
imunidade: a maior flexibilidade, nas prisões femininas, das leis criadas pelos internos (as) e o fato de ser "mãe do menino Arthur, o rei do presídio".

Rita Roberta ainda é privilegiada por ter esposo com o qual se relaciona inclusive sexualmente, quando de suas visitas à Papuda com o bonde do amor, seguidas de longas cartas do marido. As visitas e as longas cartas, com certeza, quebram-lhe a solidão e solidificam o amor. Situação rara não só entre presas não nacionais, mas também presidiárias brasileiras. Pela regra geral, as mulheres "Cumprem penas esquecidas pelos familiares, amigos, maridos, namorados e até pelos filhos" (VARELLA, 2017, p. 38).

\section{Miss do presídio, uma traficante das áfricas}

A traficante das áfricas foi privilegiada com a boa sorte e com o mérito. Com a boa sorte, porque "a brasileira era negra preferida" (DINIZ, 2015, p. 183), a mais bem dotada em todos os aspectos físicos para ascender ao status de modelo tão almejado pelas presidiárias da PFDF. Mas, a brasileira padeceu dos percalços do azar, brigou e teve o rosto arranhado, por isso foi substituída por "uma traficante das áfricas", também virtuosa porque dotada de beleza rara, daí seu indiscutível mérito e consequente recompensa. Assim como a brasileira, que deveria ser a Miss, mas não chegou lá, a segunda colocada que ocupou o trono foi escolhida pelas outras presas. O glamour da festa era de fazer inveja e a quebra de rotina do cotidiano prisional maior ainda.

As falas de Diniz (2015), em destaque, e as mensagens de Bumachar (2016), a serem mencionadas, encontram-se próximas do tempo e oferecem ao leitor informações semelhantes, quando cotejadas. O que pode ser exemplificado com o tipo predominante de crime (tráfico de drogas), a origem das migrantes, que em sua maioria vêm de parte do conjunto hoje denominado "Migrações Sul-Sul" (ROSA, MENESES, 2018) o expressivo número de mães e outras semelhanças, conforme se verá mais tarde.

O que está em foco no trabalho de Bumachar (2016, p. 43) "é a produção de uma etnografia da experiência prisional não apenas de uma coletividade presa, mas também da própria penitenciária”. O estabelecimento prisional em estudo é a PFC, a antiga Penitenciária do Estado, “construída como prisão-modelo nos anos 1920, pelo arquiteto Artur Ramos, o mesmo que projetou o Teatro Municipal de São Paulo, obra-prima da arquitetura paulistana do início do século XX” (VARELLA, 2017, p.11).

A coletividade pesquisada por Bumachar (2016, p. 41), quando contatou a PFC, tinha em volta "de 800 presas, sendo cerca de quase metade composta por não nacionais". Essas eram constituídas de "mulheres de mais de 60 nacionalidades, falantes de mais de 30 línguas, 
mas que traziam em comum, em 76\% dos casos, a maternidade, e, em 95\% dos casos, o tráfico de drogas, na função de mulas (transportadoras de droga), crime pelo qual respondiam". Além do mais, "a maioria das estrangeiras, na PFC é, igualmente, formada de infratoras primárias, residia anteriormente em seus países de origem e não falava português" (BUMACHAR, 2016 p. 41). Destaca-se que a primariedade é fato comum encontrado, da mesma forma, entre presos (as) nacionais, e presos estrangeiros no Brasil. Obviamente, na condição de forasteiras e primárias, "quase nenhuma chegava com qualquer noção das linguagens criminal e legal" vigente no país.

Os detalhes na identificação das estrangeiras progridem em quantidade e qualidade na etnografia sobre a PFC, conforme se constata, sobretudo, dos gráficos e tabelas seguintes, quando comparados às informações de Diniz (2015).

Gráfico 1. Presas na PFC - 2010

Presas no estado de São Paulo

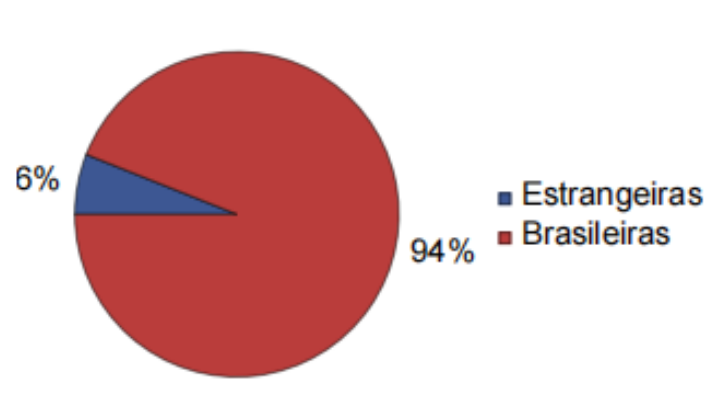

Presas na PFC

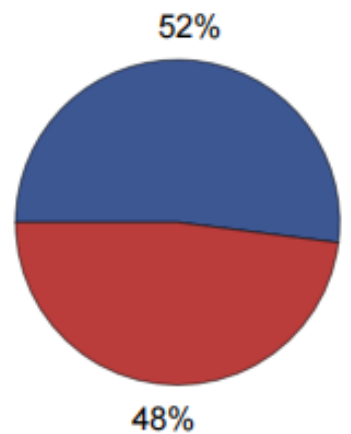

- Estrangeiras - Brasileiras

Fonte: Bumachar (2016, p. 74).

Observa-se, no Gráfico 1, que a maioria das internas, na PFC (52\%), era composta de estrangeiras, fração de uma totalidade que girava em torno de 772 presas, em junho de 2010. O percentual de forasteiras superior ao de brasileiras justifica-se, em parte, pelos esforços da Secretaria de Administração Prisional do Estado de São Paulo em prol de concentrar as presidiárias estrangeiras em único local, para facilitar planejamento e execução de políticas, bem como assistência por parte de organizações do tipo ITTC (Instituto Terra Trabalho e Cidadania), pastorais religiosas, embaixadas, consulados, dentre outras. Essas constatações, por outro lado, diferem totalmente dos dados encontrados em (DINIZ, 2015, p. 12), que numa totalidade de "quase setecentas mulheres presas", na PFDF, mencionou apenas uma fração de aproximadamente oito estrangeiras, o que se explica pela diferença entre os dois campos de pesquisa, propósitos e respectivas populações, dentre outros motivos. 
Tabela 1. Países de origem - PFC - 2010

\begin{tabular}{lcc}
\hline País & Mulheres & Percentual \\
\hline África do Sul & 56 & $13,93 \%$ \\
Bolívia & 52 & $12,94 \%$ \\
Angola & 31 & $7,71 \%$ \\
Espanha & 26 & $6,47 \%$ \\
Filipinas & 18 & $4,48 \%$ \\
Tailândia & 17 & $4,23 \%$ \\
Paraguai & 15 & $3,73 \%$ \\
Peru & 13 & $3,23 \%$ \\
Cabo Verde & 10 & $2,49 \%$ \\
Romênia & 10 & $2,49 \%$ \\
Bulgária & 9 & $2,24 \%$ \\
Malásia & 9 & $2,24 \%$ \\
Alemanha & 8 & $1,99 \%$ \\
Guiné & 7 & $1,74 \%$ \\
Nigéria & 7 & $1,74 \%$ \\
Total (parcial) & 288 & $71,64 \%$ \\
\hline
\end{tabular}

Fonte: Bumachar (2016, p. 75).

Constata na Tabela 1, em primeiro lugar, a concentração de presas procedentes da África (África do Sul, Angola, Cabo Verde, Guiné e Nigéria), em segundo, as da América do Sul (Bolívia, Paraguai, Peru), países que têm fronteiras com o Brasil, em terceiro, as da Europa com expressiva representação da Espanha, menor da Romênia e Bulgária, e insignificante presença de alemãs. Por último estão as asiáticas, provenientes das Filipinas, Tailândia e Malásia. Aproximando as informações de (DINIZ, 2015) com as contidas na Tabela 1, detecta-se que as africanas são maioria, com a diferença de que essa pesquisadora encontrou "as russas", o que não aconteceu com (BUMACHAR, 2016), que por sua vez descobriu outras estrangeiras. Também relevante é o fato de estas migrantes comporem, da mesma forma, a categoria de migração não planejada cujos membros chegaram ao Brasil sem pedir licença e com objetivos de práticas ilegais.

Tabela 2. Faixa etária - Presas estrangeiras \% - Presas no Estado de SP \% - PFC - 2009-2010

\begin{tabular}{lcc}
\hline Faixa etária & Presas estrangeiras $\mathbf{( \% )}$ & Presas no estado de SP (\%) \\
\hline Entre 18 e 24 & $27 \%$ & $19 \%$ \\
Entre 25 e 30 & $25 \%$ & $22 \%$ \\
Entre 30 e 35 & $19 \%$ & $19 \%$ \\
Entre 35 e 45 & $20 \%$ & $27 \%$ \\
Entre 45 e 60 & $8 \%$ & $12 \%$ \\
De 60 em diante & $1 \%$ & $1 \%$ \\
Total & $100 \%$ & $100 \%$ \\
\hline
\end{tabular}

Fonte: Bumachar (2016, p. 77). 
Detecta-se, na Tabela 2, a predominância de estrangeiras jovens na PFC, com maior concentração na faixa entre 18 e 24 anos, seguindo-se em menor volume as situadas entre 25 e 30, assim, sucessivamente na medida em que os estratos etários vão crescendo em idade. População significativamente mais jovem ainda do que a totalidade das prisioneiras do Estado de SP, cujo significado desaparece a partir de 45 e 50, igualando-se apenas após os 60 anos, à época da pesquisa. Em âmbito nacional, tendência semelhante foi encontrada pelo Infopen (Informações penitenciárias) em 2016: de 18 a 24 anos 27\%, sendo que a partir dessa faixa etária, a semelhança entre os dados se aproximam mais dos percentuais de mulheres presas no Estado de SP do que aos referentes às demais estrangeiras na mesma situação (Infopen Mulheres / 2018, p. 37).

Tabela 3. Atividades remuneradas - Percentual - PFC - 2009-2010

\begin{tabular}{lc}
\hline Atividades remuneradas & Percentual \\
\hline Comerciante & $29 \%$ \\
Garçonete & $6 \%$ \\
Assistente pessoal & $5 \%$ \\
Faxineira/doméstica & $5 \%$ \\
Empresária & $4 \%$ \\
Cabeleireira & $3 \%$ \\
Professora escolar & $3 \%$ \\
Duas ou mais atividades & $6 \%$ \\
Outros & $31 \%$ \\
Não consta & $8 \%$ \\
Total & $100 \%$ \\
\hline
\end{tabular}

Fonte: Bumachar (2016, p. 79).

Pela regra geral, pesquisadores do sistema prisional sabem das dificuldades para se definir uma profissão, atividade remunerada ou função econômica dentre presos (as), antes de serem apanhados (as) pela polícia. Tais dificuldades foram verificadas, inclusive, entre as forasteiras por Bumachar (2016, p. 78- 87). Conforme essa autora, 95\% das estrangeiras respondiam pelo crime de tráfico de drogas, na função de mulas, prevalecendo cocaína (78\%). Ser trabalhador (a) e, sobretudo, estar no desempenho de uma atividade econômica, ter profissão etc. geram efeito moral altamente positivo na sociedade das pessoas livres, o que é reproduzido na "sociedade dos cativos". Lá e cá, ninguém quer ser visto como preguiçoso (a), sem serviço e desqualificado (a). A maioria (29\%) das pesquisadas se declarou comerciante, profissão que envolve infindáveis subdivisões, desde alguém que esteja no mercado formal ou informal, legal ou ilegal, local, nacional ou transnacional. Talvez ainda uma única mulher 
cuide do lar, seja empregada doméstica e, em horas vagas, venda produtos entre vizinhas e se declare comerciante, se esta profissão the apresentar mais prestigiada. No quesito, "outros" tipos de atividades (31\%), subentendem-se fragmentação ocupacional e dificuldade para tipificar as profissões.

Dentre as pesquisadas despertou a atenção de Bumnachar (2016, p. 81 e 85) o depoimento de Margarida, uma "Portuguesa de verdade, branca, engenheira civil (de formação) e de classe média, como costumava se autodefinir, foi mais uma das estrangeiras a situar os fatores econômicos em motivações circunstanciais e contextuais para o transporte de cocaína" e a fala de Patrícia, [...] Outra, "uma sul-africana branca, de 23 anos, engenheira de computação que, após duas viagens bem sucedidas durante suas férias, decidiu abandonar o emprego numa multinacional em Joanesburgo para ganhar a vida transportando drogas para mais de 60 destinos".

O perfil das estrangeiras difere, com exceção da maternidade comum com a maioria, sob muitos aspectos, dos traços das presidiárias nacionais. Nessas mulheres, destacam-se o nível de escolaridade (engenharia), curso e profissão competitivos e de alto status social, somados à cor da pele (branca) e a profissão, ressaltados por Bumachar (2016). Além da engenharia e da medicina, Diniz (2015) deu relevo à "cor de lua fraca", à "beleza que incomoda", à "Miss", ao "porte de gente fina" e à "altivez", em contraste com a maioria das brasileiras, que vêm da rua e dependem do crack. "Elas são jovens, negras pobres e com filhos" [...] "Chegaram à PFDF pelo confuso tipo penal tráfico de drogas". No vértice da pirâmide educacional posiciona-se a "estrangeira" "Z", 44 anos, com pós-graduação, sem outros detalhes (SOARES, ILGENFRITZ, 2002, p 36-37). Pode-se concluir dos relatos apresentados por essas autoras que as estrangeiras não são gente que não tinham eira nem beira, pelo contrário, elas tinham "um lugar no mundo [...] eram alguém" (KUSHNER, 2019, p. 209-210).

Do mesmo contexto, fluem questões pertinentes ao gênero, como a maternidade, por exemplo, somada às condições atípicas de convivência e separação, cercadas por fronteiras prisionais e transnacionais. Entre estrangeiras, a cor da pele negra, “de cor” (coloured), ou misturada, e branca conferem status social, constituem elementos de rixa e discriminação, são elementos de classificação, trazidos pelas sul-africanas do país de origem, o que foi observado na PFC. Por outro lado, na PFDF, as expressões "jovens, negras pobres e com filhos" são termos vagos, formando um todo amplo para designar a maioria das presas. Não há sequer distinção entre brancas, pretas e pardas, conforme a tipologia que consta do IBGE (Instituto Brasileiro de Geografia e Estatística), em 2014, o que sugere indicar despreocupação da 
autora em classificar as prisioneiras pelo critério cor. A estrangeira "Z" e outras colegas de cadeia, já mencionadas, disseram ser preteridas por brasileiras ou discriminadas quanto ao trabalho.

Aproximando os dados referentes às estrangeiras encontrados na PFC com as da PFDF com depoimentos de pesquisadores (as) brasileiros (as), constata-se que a concentração na função de mulas é semelhante às informações detectadas entre as presas por tráfico de drogas, em âmbito nacional, o que se apoia em (FERNANDES, 2021, p. B4).

\section{Tradução de não nacionais para estrangeiras}

Deter-se-á agora no processo de construção, metamorfose, conversão, do ir e vir, em busca da assimilação e elaboração de um novo modo de vida, uma nova pessoa, incluindo a criação e recriação de raízes locais e transnacionais, de assunção a nova (s) identidade (s), ou seja, à transmutação em estrangeiras. (BUMACHAR, 2016, p. 41) distingue, com certa razão, as expressões "não nacionais" de "estrangeiras", o que justifica o itálico.

"Não nacionais", ou mesmo não nacional, é um termo mais abrangente e neutro, pois se refere a toda e qualquer mulher de outro país que se tornou prisioneira no Brasil. O termo estrangeira, tanto no singular quanto no plural, indica um processo, uma dinâmica que começa quando se transpõe, pela primeira vez, o portão, a grade de uma cadeia, a cela de um Departamento da Polícia Federal ou da Polícia Civil, e, talvez ainda, quando a prisioneira é jogada, na primeira ocasião, dentro de um camburão policial. Trata-se de uma trajetória complexa e complicada, rica em aprendizagem e carregada de sofrimento.

O fazer-se estrangeira desenvolve-se dentro e fora dos muros prisionais, nacionais e transnacionais porque, mesmo quando fechados, são perpassados por conhecidos e desconhecidos canais de comunicação já tradicionais, inventados e reinventados no dia a dia da prisão. Tais muros podem ser materiais, os mais conhecidos, mas também imateriais, quando assentados em normas costumeiras e na força moral das pessoas, por exemplo. Apesar de certa neutralidade e abrangência, a expressão não nacional torna-se instigante, especialmente, quando cotejada com a palavra estrangeira, no contexto destas reflexões, visto que sugere pelo menos três possibilidades inerentes à condição de forasteiras pegas pelas redes prisionais.

A primeira refere-se à condição de uma presa não nacional que permanece por longo tempo atrás das grades de uma cadeia sem que ela se torne uma estrangeira, no sentido pleno do termo em discussão, ou seja, sem haver de sua parte "inserção na prisão", o que inclui, 
principalmente, a "necessária interação no (e produção do) jogo político intramuros". Tal possibilidade, por mais incrível que pareça ao leitor, torna-se fato exemplificado pela morte de Behati. Essa "uma sul-africana branca, de 40 e poucos anos, cuja história se tornou emblemática das dores e dificuldades, entre os anos 2008 e 2009, emblemática das dores e dificuldades enfrentadas por não nacionais durante o aprisionamento" (BUMACHAR, 2016, p. 93 e 95$)$.

Apesar "dos mais de dois anos de aprisionamento, Behati não aprendeu português, menos por uma dificuldade com outras línguas e mais por uma recusa política de submissão aos poderes brasileiros vigentes na unidade, como certa vez me explicou outra sul-africana branca" (BUMACHAR, 2016, p. 93 e 95). A força de sentimentos e de ideias preconcebidas, assentados no passado, prevaleceu-lhe sobre a razão, como consequência. Isto se ergueu na principal fronteira ou muro para Behati, já limitada por outras tantas barreiras com as quais ela se defrontou, e lhe resultou em trágicos desdobramentos.

“Na ocasião das rebeliões do dia das mães, 11 de maio de 2006 (véspera), após a Tropa de Choque, da Polícia Militar, penetrar na área interna da unidade da PFS (Penitenciária Feminina de Santana), localizada na capital do Estado de São Paulo, para reprimir a rebelião neste lugar, um policial abordou Behati em português. Porque ela havia se perdido de suas parceiras e não entendia a língua e a compreensão das gramáticas intramuros permaneceu paralisada diante das incompreensíveis ordens policiais e da correria, gritaria, tiros de bala de borracha e bombas de efeito moral que circundavam seu desespero (BUMACHAR, 2016, p. 94).

O desconhecimento da língua falada e escrita, dos lados de dentro e de fora dos muros prisionais, dificultou-lhe igualmente a inserção tanto dentro quanto fora da cadeia, isto é, negou-lhe a aproximação dos costumes, a internalização de códigos e traquejos elementares. Nem sua vida foi salva por sua incipiente desenvoltura no uso da gramática carcerária, mas pela sabedoria de um agente prisional conhecedor da cultura de seu meio, onde o grito, às vezes, faz mais efeito do que o diálogo ou o silêncio.

Em situação de extramuros prisionais, Behati, já amparada pela solidariedade humana e pela execução das normas do Estado que lhe aprisionou, foi conduzida "ao hospital", lugar em que também a falta de traquejo no emprego do português lhe custou caro, pois "passou maus bocados [...] para tomar a medicação diária para seus problemas respiratórios”.

Os diferentes tipos de deficiência cultural, o não enraizamento no local onde se encontrava e o (des) enraizamento do país de origem transformaram aqueles que lhe estavam 
próximos (médicos, enfermeiras, enfermos etc.) em distantes e aquele que era distante em próximo, o que foi o caso do agente penitenciário que a salvou.

O hospital para onde essa sul-africana foi levada poderia ser uma cela transformada em enfermaria, o que faria dessa cela um ambiente distinto do anterior, mas dentro dos muros prisionais. Lugar diferente em decorrência da separação de funções, uma vez que o hospital serve para curar e a cadeia para prender, logo um fora, mas, ao mesmo tempo, um dentro e um dentro, porém fora. Contudo, o hospital poderia estar em outro lugar, perto ou distante dos muros prisionais, e aberto a toda e qualquer categoria de cidadão, não importando sua procedência, sexo ou cor de pele. Ao acolher Behati, com certeza, na condição de prisioneira, ela estaria escoltada e algemada ao leito. A partir desse momento, a cama hospitalar que se encontrava fora (dos muros prisionais), transformar-se-ia num lugar de dentro (da cadeia) para a infeliz sul-africana branca. A partir dessa ocasião, tal leito se transmutaria numa prisão, ou seja, em um fora, porém dentro, ao acolher essa presa recém-chegada.

As fronteiras prisionais, mesmo no interior de um Estado nacional, uma Comarca e cadeia nem sempre são tão fixas como parecem, porque podem se mover e mudar de identidade juntamente com o deslocamento do prisioneiro, seja homem, mulher, brasileiro, não nacional ou estrangeiro (a), o que se deu com esta forasteira.

Em decorrência de frágeis conexões entre seus pares, precários laços institucionais, raras ligações de dentro e de fora dos muros, ruptura com os liames familiares e nacionais, Behati não se tornou uma estrangeira, no cotidiano prisional e transnacional, aliás, "Veio a falecer na casa de acolhida em função de seus problemas respiratórios" (BUMACHAR, 2016, p. 95-96) sem realizar o sonho de se reconciliar com os seus e com a pátria.

A segunda possibilidade contida na expressão "não nacional" refere-se à condição de uma presa que se encontra em situação de limbo ou de margem, isto é, que esboça os primeiros sintomas da tomada de consciência do novo lugar. Lugar circunscrito por muros, grades e uma cultura totalmente estranha para quem se encontra na soleira ou acaba de adentrar. Essa cultura compreende, entre outros elementos, o domínio da língua portuguesa, o conhecimento dos códigos penais oficiais e os construídos pelos presos (as), a compreensão da linguagem do mundo do crime e da cadeia etc. Ir além deste limbo significa muito mais do que transpor muros e grades, todavia sem a posse da chave da fechadura. Percorrer este limbo significa ensaiar os primeiros passos da longa caminhada para se tornar uma estrangeira no cotidiano da prisão. Nos primeiros dias e meses, tais maneiras de operar são percebidas como longas e custosas, sobretudo, porque dolorosas, não apenas para o corpo, mas principalmente 
para a alma, conforme ouviu e escreveu Diniz (2015, p. 145-147), a respeito de Juanita, uma colombiana que engatinhava no ritual de iniciação.

Diferente de Behati, Juanita, destacou-se das presas pela língua (espanhol), origem (Colômbia), pelo crime (agiotagem, extorsão, lesão corporal, formação de quadrilha) e principalmente pela beleza. "No dentro e no fora ela seria uma mulher linda. A beleza é incômoda de realidade daquele corpo naquele lugar" (DINIZ, 2015, p. 145). Incômodo porque no interior desse presídio tudo parece feio, enfumaçado, fedorento. A quase totalidade das presas habitava as ruas, dependiam do crack, chegavam molambentas. Aliás, tal feiura encontra-se muito bem exemplificada através da multiplicação e promiscuidade entre presas e baratas: "As baratas disputam crescimento populacional com presas, incontáveis nascem das grades, escondem-se nas roupas, passeiam pelo corpo", penetram em seus orifícios, preferencialmente no ouvido. A propósito desta feia e confusa realidade, ainda acrescentou “Uma multidão de mulheres abandonadas". [...] "Na multidão, estão as grávidas, as doentes, as velhas ou as muito jovens, as estrangeiras, as loucas e as líderes" (DINIZ, 2015, p. 10). Semelhante à Behati, Juanita não conhecia as gírias da cadeia, nem o português falado pela quase totalidade das colegas e pelo pessoal administrativo.

$\mathrm{Na}$ condição de uma dentre as poucas "estrangeiras" presas na PFDF, Juanita, mesmo sendo afligida pela experiência de que "Estava sendo difícil viver, aprender os modos do presídio custava muito", conforme Diniz (2015, p. 147), dava sinais dos primeiros passos no processo de aprendizagem da cultura da cadeia, no que diz respeito aos "modos de falar" e de dormir do presídio. Aprendeu dizer e entender corretamente o significado de comida melhorada. Aprendeu e adaptou-se a dormir de valete (uma para cada lado do colchão), dormir na jega (cama de concreto para três) e dormir na praia (no chão) etc. Disse que "a saudade ia sumindo", ou seja, novas raízes estavam sendo criadas e vínculos anteriores se enfraqueciam.

Tais posturas são sintomas dos processos sociais, inicialmente, carregados de conflito, porém mesclados de convivência, acomodação e assimilação, todavia a duras penas, obviamente. Em parte, a perda da saudade, a conta gotas, justifica-se pelo abandono mais imaginado, sentido e sofrido do que real, pois teve visita dos pais, mesmo sendo uma única vez, e recebia ligações telefônicas a cada quinze dias. Ainda assim, enfatizou a pesquisadora, ao falar de Juanita: "Ela é estrangeira, não tanto pelas palavras, mas pela solidão. A verdadeira estrangeira é aquela que nunca recebe visita. Juanita é uma delas" (DINIZ, 2015, p. 145-147). Três meses é tempo curto para interagir com seus pares e com a administração. Sua língua não é entendida e os meandros do cárcere são mais complicados ainda. Todavia a 
colombiana já iniciara os primeiros passos pelo estranho e intrincado mundo prisional, percorrendo as vias que a conduzirão à posição de uma estrangeira nos limites da PFDF, ou seja, à assunção a uma nova identidade, isto é, a "um lugar que se assume, uma costura de posição e contexto, e não uma essência ou substância a ser examinada" (HALL, 2003, p. 15$16)^{3}$.

A terceira possibilidade refere-se à condição de uma presa não nacional que se torna estrangeira, ou seja, que assume o status de uma "cidadã" da sociedade intramuros (a cadeia) e a transnacional (o país de origem). Foi o que aconteceu com "Caitlin, sul-africana branca, de 20 e bem poucos anos" (BUMACHAR, 2016, p. 103).

Um dos principais problemas dessa sul-africana começou "quando Caitlin decidiu expor, em seu julgamento, todos os detalhes de seu aliciamento e sua situação no transporte de cocaína, tendo em vista a denominada delação premiada" ou colaboração premiada. Durante essa delação a forasteira "revelou o nome, os números de telefone e os locais de circulação do nigeriano (negro), não necessariamente originário da Nigéria, responsável pelo seu embarque na capital paulista" (BUMACHAR, 2016, p. 103-104). Como consequência do que consta no relato apresentado, a sul-africana estava sendo punida por dois tipos de legislação. A primeira procedia da lei penal do Estado brasileiro por crime de tráfico de drogas, o tipo de enquadramento de "95\% dos casos" de estrangeiras presas na PFC, no qual essas mulheres desempenham a função de mulas. A segunda lei penal que apanhou Caitlin pertencia à legislação produzida, à margem da primeira, pelos criminosos e pelos prisioneiros que, tanto fora quanto dentro dos muros prisionais, castiga cruelmente o (a) caguete (alcagueta).

Em cadeia masculina a caguetagem (delação) é punida com a morte do delator. Por outro lado, o (a) caguete é geralmente bem vindo por algumas autoridades dentro e fora do cárcere, porque este lhes traz informações preciosíssimas, o que facilita ao delator o pedido e a concessão do seguro (proteção), antes que receba a penalidade merecida. Por sua vez, em cadeia feminina, "as leis são semelhantes, assim como a hierarquia é estabelecida pelo mesmo processo de competição e seleção, com a diferença de que o respeito a ela é mais frouxo". Além do mais, "A imposição de normas e as relações de mando, tão lineares entre homens presos, adquirem complexidade incomparável no caso das mulheres, porque as emoções entram em jogo com o mesmo peso da racionalidade" (VARELLA, 2017, p. 20).

\footnotetext{
${ }^{3}$ A pesquisadora BUMACHAR pôs "em suspeição os limites epistemológicos que fundamentam noções como as do "maior isolamento prisional" e da "tripla condenação/penalização" das não nacionais, em meio às tensões e assimetrias de (gênero, raça, regionalidade, nacionalidade etc.) constitutivas e constituintes de seus respectivos aprisionamentos" (BUMACHAR, 2016, p. 40).
} 
Relevando-se as particularidades relacionadas às prisões femininas, há pouco mencionadas, acrescenta-se que Caitlin, ao se tornar uma estrangeira na prisão, já tinha aprendido e assimilado vários saberes componentes dos códigos do Estado, do mundo do crime e da cadeia, tanto em âmbito local (interno e externo à prisão) quanto transnacional.

O domínio e a instrumentalização destes saberes estavam perfeitos, muito bem planejados e dosados, porém como toda e qualquer aprendizagem nunca é completa, da mesma forma, o se fazer estrangeira é um processo contínuo, nunca acabado, parafraseando (BUMACHAR, 2016), Caitlin tropeçou em um dos artigos do código de conduta, muito embora ela o conhecesse, a lei do silêncio: "Não ver, não ouvir, não falar” (SÁ, 1996, p. 174). "Ao longo de seu julgamento, ouvi dizer que Caitlin estava falando demais do que deveria dentro da Penitenciária Feminina da Capital, causando indignação de algumas africanas" (BUMACHAR, 2016, p. 104). Indignação não tanto pela delação em si, mas porque o delatado era o nigeriano preto. Esse e outros nigerianos usufruíam de alto prestígio, sobretudo entre as sul-africanas negras, lembrando-se de que a delatora era sul-africana branca. Prestígio assentado principalmente no poder resultante de sua posição hierárquica no mundo do crime. O delatado além de aliciador fora responsável pelo seu embarque no aeroporto internacional de Guarulhos com a finalidade de transportar cocaína para a Europa, enquanto a delatora era mula, uma subordinada, com função de subalternidade na engrenagem criminosa. Não se tratava, portanto de uma delação entre iguais. Além da posição hierárquica, este e outros nigerianos eram influentes e dominavam segredos dos circuitos do tráfico de drogas locais, nacionais e internacionais, inacessíveis às mulas. Pelo traquejo, bravura, tipo físico, virilidade e outros dotes, eram também os preferidos, principalmente, das sul-africanas negras como maridos e namorados, agentes de confiança etc. (BUMACHAR, 2016).

O desrespeito ao "código do silêncio, por falar mais do que se deve”, e ao código da eterna vigilância, "dormir com um olho na missa e o outro no padre" (COLEHO, 2005, p. 92-94), empurrou Caitlin para o centro de um complexo jogo de forças perpassado por questões de raça, gênero, miscigenação, hierarquia e nacionalidade, dentre outras, e no qual o sentimento falou mais alto do que a razão, do que a solidariedade entre patrícias e a intramuros etc. Apesar da complexidade da situação, a delatora manteve serenidade, mesmo porque ela sabia muito bem caminhar por este campo minado. Pelos conhecimentos e práticas acumulados, a sul-africana branca previa como de fato aconteceu: as outras prisioneiras, brasileiras e estrangeiras, permaneceram alheias ao incidente e suas consequências, com exceção das respectivas compatriotas. Seu domínio sobre a situação era de tal amplitude que ela não solicitou seguro às autoridades da instituição, apesar dos malefícios direcionados à sua 
pessoa. Por sua vez, [...] "diante das ameaças destinadas a Caitlin, a direção da disciplina, principal responsável pelas questões de segurança da unidade, decidiu retirá-la da área de convívio, o oposto da cela de castigo e de seguro". A confiança de Caitlin em seus inumeráveis saberes acumulados fez com que "ela e sua namorada - também sul-africana, porém “de cor" (coloured) - tentassem reverter tal decisão, uma vez que elas não queriam se separar", (BUMACHAR, 2016, p. 106-107). O casal, cego pela paixão e pelo medo da separação, insistia veementemente junto à administração sobre a desnecessidade do seguro. A paixão rompeu barreiras, inclusive, a de status inter-racial, uma tradição cultivada no país de origem. As "de cor" (coloured), por não serem nem brancas e nem pretas, mas misturadas, ocupavam posição de inferioridade na hierarquia racial construída na África do Sul, sendo discriminadas igualmente entre as estrangeiras procedentes desta nação, na PFC (BUMACHAR, 2016). Ao se apaixonar por uma impura, uma miscigenada ou híbrida, o que transparecia através da cor de pele, as patrícias tiverem mais um motivo sério para acusar Caitlin de cagueta. Apesar da insistência do casal para permanecer no convívio da cadeia "imperou o poder de decisão da agente do Estado". "Dali em diante, Caitlin cumpriria toda a sua pena no seguro". "E o namoro seria vivido por entre fronteiras intramuros" (BUMACHAR, 2016, p. 107). Final feliz para o casal, cujas nubentes se fizeram estrangeiras "no fazer cotidiano dos limites da prisão".

\section{Considerações finais}

Nas penitenciárias femininas analisadas, nem sempre há alas ou pavilhões próprios para as presas de outras nacionalidades, sendo que na PFDF a mistura é mais complexa, pois abrange as internas em cumprimento de medida de segurança, conhecidas como "as loucas".

Houve inovação conceitual ao se estabelecer distinção entre os termos "não nacional" e "estrangeira". Atribuindo-se ao primeiro caráter mais neutro e abrangente e ao segundo caráter mais dinâmico e específico. O primeiro compreende a totalidade das presas de outras nacionalidades. O segundo refere-se especialmente ao longo, árduo e contraditório processo de integração da não nacional nos códigos da cadeia, do mundo do crime e do Estado que a prendeu, o que lhe permite sobreviver e "transitar" entre o local e o transnacional. Todas são estrangeiras, mas nem todas se fazem estrangeiras.

Confirmou-se, mais uma vez que o abandono sofrido pelas mulheres presas é superior ao dos homens nas mesmas condições, inclusive em âmbito continental. Por sua vez, as pesquisadoras contatadas confirmaram que o abandono sofrido pelas estrangeiras é superior ao das brasileiras. Por outro lado, Bumachar (2016), em tese, concorda com esta afirmação, 
porém, levanta suspeição sobre o tríplice isolamento: o fato de estar em prisão, de ser mulher e estrangeira. Fundamentada no processo de "se fazer estrangeira nos limites da prisão", essas ultrapassam fronteiras locais e transnacionais.

As motivações para o crime são prevalentemente econômicas, mas não de natureza puramente econômica, todavia mista. A maioria se dizia ter profissão antes do crime e estar trabalhando. Algumas com curso superior e bons empregos entraram para o tráfico de cocaína pelo prazer de viajar com todas as despesas pagas e ganhos elevados. Bom emprego, curso superior e distanciamento de ex-marido. Emprego razoável, contudo, insuficiente para ter uma casa de alvenaria para os filhos e outros familiares etc.

As presas descritas são, em sua maioria primárias, muitas mais jovens do que a média das brasileiras encarceradas, mães e de status mais alto. Aproximam das nacionais na função de mulas, isto é, de subalternidade na logística do tráfico de drogas proibidas.

$\mathrm{O}$ continente africano aparece mais representado nas prisões femininas, enquanto a Ásia se faz presente apenas com Filipinas e Malásia.

\section{Referências Bibliográficas}

BRASIL, Congresso Nacional. Lei $n^{\circ} 13.445$, de 24 de maio de 2017. DOU de 25-05-2017. , Assembleia Nacional Constituinte. Constituição da República Federativa do Brasil. DOU n. 191- a., de 5-10-1988.

, Congresso Nacional. Lei n. 7.210, de 11 de julho de 1984, art. 89, com os acréscimos determinados pela Lei n. 11. 942, de 28 de maio de 2009.

Ministério da Justiça e Segurança Pública. Levantamento Nacional de Informações Penitenciárias. INOPENMULHERES. 2ed. 2018.

BUMACHAR, B. L. Nem dentro, nem fora: a experiência prisional de estrangeiras em São Paulo. Tese (Doutorado) - Instituto de Filosofia e Ciências Humanas, Universidade Estadual de Campinas, Campinas, 2016, 378 p.

COELHO, E. C. Oficina do diabo e outros escritos sobre criminalidade. Org. Magda Prates Coelho. Rio de Janeiro/São Paulo: Record, 2005.

DINIZ, D. Cadeia: relato sobre mulheres. Rio de Janeiro: Civilização Brasileira, 2015. 371 p.

FERNANDES, M. Folha de São Paulo, São Paulo, Caderno B, p. 4, 2001.

FILLÓ, A. Diário de Tremembé: o presídio dos famosos. São Paulo: Nova Esperança Brasil, 2019. 
JOHNSON, A. G. Dicionário de sociologia: guia prático da linguagem sociológica. Trad. de Ruy Jungmann. Rio de Janeiro: Zahar, 1997.

HALL, Stuart. Da Diáspora: identidades e mediações culturais. Belo Horizonte: Editora UFMG; Brasília: UNESCO, $2 \mathrm{OO} 3$.

IBGE (Instituto Brasileiro de Geografia e Estatística) / Pnad (Pesquisa Nacional por Amostra de Domicílios) - 2014. Agência Brasil - Acesso em: 21/08/2021.

LEMGRUBER, J. Cemitério dos vivos: análise sociológica de uma prisão de mulheres. Rio de Janeiro: Achiamé, 1983, 142 pp.

KUSHNER, R. Mars club. Trad. de Rogério W. G. São Paulo: Todavia, 2019.

ROSA; MENESES. Entre migrações e refúgio: migrações sul-sul no Brasil e as novas tipologias migratórias. In: BAENINGER, R. et al. Migrações sul-sul. UNICAMP: Campinas, 2018, p. 398. Disponível em: https://nempsic.paginas.ufsc.br/files/2015/02/LIVROMIGRA\%C3\%87\%C3\%95ES-SUL-SUL.pdf . Acesso em: 30 nov. 2018.

SOARES, B. M.; ILGENFRITZ, I. Prisioneiras: vida e violência atrás das grades. Rio de Janeiro: Garamond, 2002, 150 p.

SÁ, G. R. A prisão dos excluídos: origens e reflexões sobre a pena privativa da liberdade. Juiz de Fora/Rio de Janeiro: EDUFJF/Diadorin, 1996.

VARELLA, D. Prisioneiras. São Paulo: Companhia das Letras, 2017. 